\title{
The Stability of a Ketamine-Morphine Solution
}

\author{
Roger Schmid, MD*, Gideon Koren, MD, FACMT, FRCPC广், Julia Klein, MSł̇, and Joel Katz, PhD*§
}

*Department of Anesthesia and Pain Management, Toronto General Hospital; $†$ Departments of Pediatrics, Pharmacology, Pharmacy, Medicine, and Medical Genetics, University of Toronto and The Research Institute, $\dagger$ Division of Clinical Pharmacology/Toxicology, Hospital for Sick Children; §Departments of Anesthesia and Public Health Sciences, University of Toronto, and Department of Anesthesia and Pain Management, Mount Sinai Hospital, Toronto, Canada

Recent advances in acute pain mechanisms and management have implicated the $N$-methyl $\mathrm{d}$ aspartate receptor-ion channel complex in the development of postoperative hyperalgesia and acute opiod tolerance. $N$-methyl d-aspartate receptor antagonists such as ketamine have been used increasingly in clinical studies in an effort to minimize acute postoperative pain and reduce opiod requirements. A mixture of ketamine and an opiod administered in the same solution and syringe would be a practical and useful technique for postoperative epidural analgesia, continuous IV infusion, or patient-controlled IV analgesia. We investigated the stability of a morphine sulfate and racemic ketamine solution in saline at $\mathrm{pH} 5.5-7.5$ over a period of 4 days. Our study demonstrates that the ketamine morphine mixture at a clinically relevant concentration seems to be stable at room temperature, at a wide range of $\mathrm{pH}$ values, for at least 4 days.
A dvances in the understanding of acute pain

mechanisms have led to a renaissance of the use of ketamine hydrochloride because of its actions as an $\mathrm{N}$ methyl d-aspartate receptor antagonist (1). Clinical studies have reported improved pain relief using ketamine as an adjunct to various analgesics in the treatment of acute postoperative pain (2-5) and cancer pain (6).

Of particular interest is the combination of smalldose ketamine with opioids, the most commonly used drugs for postoperative pain relief. In the clinical setting, subanesthetic doses of ketamine administered with opioids reduced opioid requirements and opioidrelated adverse effects $(2,7,8)$ perhaps because of the ability of small-dose $N$-methyl d-aspartate antagonists to interfere with the development of acute opioid tolerance (9) and opioidinduced hyperalgesia $(10,11)$.

A mixture of ketamine and an opioid administered in the same solution and syringe would be a practical and useful technique for postoperative epidural analgesia, continuous IV infusion, or patient-controlled IV analgesia. However, to administer such a mixture of drugs safely to the patient over a period of several days, one must ensure that the mixture demonstrates physical and chemical stability. Because morphine is the most frequently used opioid for the treatment of acute and chronic pain, we investigated the stability of a morphine sulfate and racemic ketamine solution in saline at $\mathrm{pH} 5.5-7.5$ over a period of 4 days.

\section{Materials and Methods}

To prepare the stock solutions, the following materials were used: 1 20-mL vial of ketamine hydrochloride (Ketalar@; Parke-Davis, Scarborough, ON, Canada) containing $10 \mathrm{mg} / \mathrm{mL}$ ketamine; $21-\mathrm{mL}$ vials of morphine sulfate $15 \mathrm{mg} / \mathrm{mL}$ (Abbott Laboratories, Ltd., SaintLaurent, QC, Canada); $21-\mathrm{mL}$ vials of morphine sulfate 10 $\mathrm{mg} / \mathrm{mL}$ (Abbott Laboratories); $11-\mathrm{mL}$ vial of morphine sulfate $2 \mathrm{mg} / \mathrm{mL}$ (Abbott Laboratories); $\mathrm{NaCl}, \mathrm{NaOH} 10 \mathrm{~N}$, HCl $6 \mathrm{~N}$ (Fisher Scientific Ltd., Nepean, ON, Canada).

A stock solution of $0.9 \% \mathrm{NaCl}$ was prepared in water; 50 $\mathrm{mL}$ was aliquoted, and the $\mathrm{pH}$ of each aliquot was adjusted to $5.5,6.0,6.5,7.0$, and 7.5. The ketamine and morphine were mixed together in the saline at $\mathrm{pH} 5.5-7.5$ at a final concentration of $1.33 \mathrm{mg} / \mathrm{mL}$ for ketamine and $2.0 \mathrm{mg} / \mathrm{mL}$ for morphine. The total volume of the solution was $25 \mathrm{~mL}$. As soon as the mixtures were ready, $61.0-\mathrm{mL}$ aliquots were taken and kept at $20^{\circ} \mathrm{C}$ in Falcon polystyrene tubes until analysis. The remaining solution was kept at room temperature, also in Falcon polystyrene ubes, for the subsequent 4 days. Each day, the same exercise was repeated: $1.0 \mathrm{~mL}$ was aliquoted in 6 small vials. They were placed immediately at $20^{\circ} \mathrm{C}$ and kept there until analysis. For ketamine analysis, a high-pressure liquid chromatography (HPLC) method (12) was used with some modifications. Briefly, the mobile phase was $0.1 \mathrm{M}$ sodium dihydrogen phosphate buffer $\mathrm{pH} 2.1$ (adjusted with phosphoric acid) containing $1 \mathrm{mM}$ dodecyl sulfate and $22 \%$ acetonitrile. The flow rate was $0.8 \mathrm{~mL} / \mathrm{min}$ and the 
Table 1. Mean Ketamine and Morphine Concentrations and CV Across Days 1-4 at pH 5.5-7.5

\begin{tabular}{llllll}
\hline & \multicolumn{5}{c}{$\mathrm{pH}$} \\
\cline { 2 - 5 } & 5.5 & 6.0 & 6.5 & 7.0 & 7.5 \\
\hline Ketamine & $1.52 \mathrm{i}$ & 1.446 & 1.391 & 1.345 & 1.525 \\
$\quad$ Mean concentration $(\mathrm{mg} / \mathrm{mL})$ & 2.348 & 3.874 & 1.048 & 3.385 & 1.614 \\
CV Days 1-4 & 1.49 & & & & \\
$\quad$ Overall mean & 9.40 & & & & \\
CV pH 5.5-7.5 & & & & & 2.317 \\
Morphine & 2.485 & 2.336 & 2.264 & 3.091 & 1.666 \\
$\quad$ Mean concentration (mg/mL) & 2.181 & 4.454 & 1.226 & & \\
CV Days 1-4 & 2.362 & & & & \\
Overall mean & 7.905 & & & & \\
CV pH 5.5-7.5 & & & & \\
\hline
\end{tabular}

CV_ coefficient of variation.

column was Prodigy ${ }^{\mathrm{TM}}$ ODS (3) 5 m, $150 \ldots 4.6 \mathrm{~mm}$ (Phenomenex, Torrance, CA). We used a Shimadzu HPLC system equipped with a spectrophotometric detector set at $215 \mathrm{~nm}$ (Mandel Scientific, Guelph, ON, Canada). For quantitation, a standard solution in saline was prepared from the same Ketalar vial that was used for sample preparation. For morphine analysis, the same HPLC method was used. For quantitation, an aliquot from a new vial of morphine sulfate $2 \mathrm{mg} / \mathrm{mL}$ was used. In addition, morphine was also measured in each sample by using an enzyme-linked immunosorbent assay method. The StatView@ SE program (SAS Institute Inc., Cary, NC) was used for statistical analysis. The mean concentration of ketamine and morphine was calculated each day. Withinthe-day and between-the-days coefficient of variation was calculated for each compound.

\section{Results and Discussion}

Our study demonstrates that the ketamine-morphine mixture at a clinically relevant concentration seems to be stable at room temperature, at least for four days at a wide range of $\mathrm{pH}$ (Table 1). Initially, we examined the stability of the solution at pH 5.5 only; however, although the ketamine seemed to be very stable, the morphine results were more erratic. There was no clear pattern of concentration decrease in time, but the coefficient of variation was rather high. The same pattern was observed using both methods of analysis: HPLC and enzyme-linked immunosorbent assay. In the present stability study, we therefore modified the original HPLC method (12) by adding an ion pairing agent to the mobile phase; the ketamine results were unchanged, but the coefficient of variation for morphine decreased considerably, from 11.04 to 2.18 at this particular $\mathrm{pH}$ (Table 1). There is some indication in the literature (13) that, at $\mathrm{pH}$ higher than 5.9, the mixture is no longer stable. However, in that study, much larger concentrations (i.e., ketamine $41.2 \mathrm{mg} / \mathrm{mL}$ and morphine $17.6 \mathrm{mg} / \mathrm{mL}$ ) were used and the $\mathrm{pH}$ was adjusted with sodium bicarbonate. We conclude that a ketaminemorphine solution can be used at physiologic $\mathrm{pH}$, at the abovementioned concentrations and that it is stable for up to four days at room temperature.

\section{References}

1. Schmid RL, Sandler AN, Katz J. Use and efficacy of lowdoseketamine in the management of acute postoperative pain: a review of current techniques and outcomes. Pain 1999;82:111-25.

2. Suzuki M, Tsueda K, Lansing PS, et al. Small-dose ketamine enhances morphine-induced analgesia after outpatient surgery. Anesth Analg 1999;89:98-103.

3. Lauretti GR, Azevedo VM. Intravenous ketamine or fentanyl prolongs postoperative analgesia after intrathecal neostigmine Anesth Analg 1996;83:766-70.

4. Himmelseher S, Ziegler-Pithamitsis D, Argiriadou H, et al. Smalldose $S(\neg$ )-ketamine reduces postoperative pain when applied with ropivacaine in epidural anesthesia for total knee arthroplasty. Anesth Analg 2001;92:1290-5.

5. Reeves M, Lindholm DE, Myles PS, et al. Adding ketamine to morphine for patient-controlled analgesia after major abdominal surgery: a double-blinded, randomized controlled trial. Anesth Analg 2001;93:116-20.

6. Berger JM, Ryan A, Vadivelu N, et al. Ketamine fentanylmidazolam infusion for the control of symptoms in terminal life care. Am J Hosp Palliat Care 2000;17:127-34.

7. Adriaenssens G, Vermeyen KM, Hoffmann VL, et al. Postoperative analgesia with i.v. patient-controlled morphine: effect of adding ketamine. Br J Anaesth 1999;83:393-6.

8. Javery KB, Ussery TW, Steger HG, Colclough GW. Comparison of morphine and morphine with ketamine for postoperative analgesia. Can J Anaesth 1996;43:212-5.

9. Kissin I, Bright CA, Bradley EL Jr. The effect of ketamine on opioid-induced acute tolerance: can it explain reduction of opioid consumption with ketamine-opioid analgesic combinations? Anesth Analg 2000;91:1483-8.

10. Celerier E, Rivat C, Jun $Y$, et al. Long-lasting hyperalgesia induced by fentanyl in rats: preventive effect of ketamine. Anesthesiology 2000;92:465-72.

11. Li X, Angst MS, Clark JD. Opioid-induced hyperalgesia and incisional pain. Anesth Analg 2001;93:204-9.

12. Mathisen LC, Skjelbred P, Skoglund LA, Oye I. Effect of ketamine, an NMDA receptor inhibitor, in acute and chronic orofacial pain. Pain 1995;61:215-20.

13. Lau MH, Hackman C, Morgan DJ. Compatibility of ketamine and morphine injections. Pain 1998;75:389-90. 